\title{
METABOLISMO DE CÁLCIO E FÓSFORO EM OVINOS
}

GUEDES, Luciana Freitas ${ }^{1}$ ANDRÉ JÚNIOR, José ${ }^{1}$

ALVES, Leonardo de Rago Nery ${ }^{2}$

ANDRADE, Pedro Augusto Dias ${ }^{3}$ VITOR, Cimara Gonzaga ${ }^{1}$

BORGES, Ana Luiza Costa Cruz ${ }^{1}$

BORGES, $\operatorname{Iran}^{1}$

ISSUE DOI: $10.3738 / 21751463.1593$

RESUMO: Realizou-se com essa revisão descrever o metabolismo de cálcio e fósforo em ovinos assim como discutir os fatores inerentes a absorção desses minerais. A importância desse estudo se deve ao aumento crescente das necessidades desses minerais na dieta devido ao melhoramento genético dos animais, à reprodução de animais jovens, às deficiências de fósforo, a crescente incidência de partos duplos, ao aumento do uso de dietas com alta densidade energética e à incidência de hipocalcemia recorrente no rebanho ovino nacional. A taxa de absorção de cálcio a partir do intestino aumenta de forma constante durante toda a gestação, entretanto é insuficiente para atender aos requisitos da ovelha no final da gestação e início de lactação. Pesquisas relacionadas ao aproveitamento de $\mathrm{P}$ por ruminantes bem como as fontes dietéticas desse elemento ainda devem ser elaboradas devido ao elevado custo desse mineral na mistura mineral.

Palavras-chave: Absorção. Cordeiro. Exigência mineral. Ovelha

\section{METABOLISM CALCIUM AND PHOSPHORUS IN SHEEP}

SUMMARY We conducted with this review describe the calcium and phosphorus metabolism in sheep as well as discuss the factors inherent absorption of these minerals. The importance of this study is due to the increasing needs of these minerals in the diet due to the breeding of animals for breeding young animals, the phosphorus deficiencies, the increasing incidence of twin births, the increased use of diets with high energy density and the incidence of recurrent hypocalcaemia in the national sheep flock. Calcium absorption rate from the intestine increases steadily throughout pregnancy, however is insufficient to meet the requirements of the ewe in late pregnancy and early lactation. Research related to the use of $\mathrm{P}$ by ruminants, and dietary sources of this element must still be developed due to the high cost of this mineral in the mineral mixture.

Keywords: Absorption. Lamb. Mineral. Requirement. Sheep

\section{INTRODUÇÃO}

O cálcio $(\mathrm{Ca})$ pode ser considerado o mineral mais importante na produção animal, pois desempenha inúmeras funções básicas no organismo relacionadas à integridade do esqueleto, à manutenção da permeabilidade normal das células, à coagulação do sangue e à regulação da

\footnotetext{
${ }^{1}$ Departamento de Zootecnia - Nutrição e Alimentação de Ruminantes. Universidade Federal de Minas Gerais

${ }^{2}$ Departamento de Medicina Veterinária. Centro Universitário Newton Paiva

${ }^{3}$ Departamento de Ciências Agrárias - Zootecnia. Instituto Federal de Minas Gerais - Campus Bambuí
} 
excitabilidade neuromuscular. Nas últimas décadas, vários fatores na produção de ovinos se combinaram para aumentar de forma constante as necessidades de cálcio na dieta, com destaque para: (i) melhoramento genético dos animais, resultando em um crescimento mais rápido e rendimentos mais elevados; (ii) aumento do uso de dietas com alta densidade energética; (iii) desmame precoce com a mudança de dieta líquida para sólidos, a partir do qual o cálcio é relativamente pouco absorvido; (iv) reprodução de animais imaturos, enquanto eles ainda estão em estágio de crescimento; e (v) aumento da incidência de partos duplos.

Juntamente ao $\mathrm{Ca}$, o fósforo (P) são os minerais mais abundantes no organismo animal

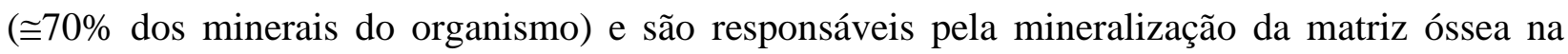
forma de $\mathrm{Ca}_{3}\left(\mathrm{PO}_{4}\right)_{2}$ e $\mathrm{Ca}_{10}\left(\mathrm{PO}_{4}\right)_{6}$ conferindo rigidez e estrutura de sustentação para a musculatura. Apesar de também exercer inúmeras funções no organismo animal principalmente ligadas ao metabolismo (componente do ATP, ácidos nucleicos, fosfolipídeos), o P é comumente referenciado como limitante da produção. Devido à deficiência generalizada desse mineral nas pastagens do Brasil Central e a maioria dos sistemas de produção de ovinos ser extensivo, é comum observar animais com sintomas de deficiência de P (destacam-se apetite depravado, perda de peso e redução do crescimento) sendo indispensável a suplementação mineral.

Portanto, devido ao elevado grau de importância desses minerais na saúde do animal e à intensa participação nas atividades metabólicas, objetivou-se com essa revisão descrever o metabolismo de cálcio e fósforo em ovinos assim como discutir os fatores inerentes a absorção desses minerais.

\section{O ESTUDO DE METABOLISMO DE MINERAIS EM PEQUENOS RUMINANTES}

O estudo especificamente em metabolismo de minerais em ovinos tem relatos desde os anos 30 com destaque para o trabalho de Morris e Ray (1939) ao avaliarem o efeito de dietas deficientes em fósforo sobre o metabolismo de proteína e minerais. Naquele momento, a maioria das discussões eram baseadas nos resultados de ingestão e excreção do elemento pelos animais. Já na década de 80, as pesquisas foram aprimoradas e as discussões eram feitas a partir da deposição de minerais em cada compartimento do animal a fim de investigar como é a dinâmica de minerais num determinado período, e.g. ao longo da gestação (GRACE 1983a; GRACE 1983b; GRACE et al., 1986).

Com intuito de evitar o sacrifício dos animais experimentais, as técnicas mais comumente aplicadas no estudo do metabolismo de minerais é o balanço convencional (digestibilidade aparente) e o uso de marcadores isotópicos, sendo esse último o método mais preciso. Traçadores radioativos têm sido utilizados para compreender o metabolismo bem como a distribuição dos 
minerais, especialmente do fósforo $(\mathrm{P})$, por meio de modelos matemáticos envolvendo o fluxo entre os diversos compartimentos do organismo animal (VITTI et al., 2000; VITTI et al., 2005) e sendo analisadas por programas de computadores.

$\mathrm{O}$ radioisótopo ${ }^{32} \mathrm{P}$ é o mais comumente marcador plasmático empregado para estudar o metabolismo de $\mathrm{P}$ no organismo. Um modelo de quatro pools ou compartimentos (trato gastrintestinal, plasma, ossos e tecidos moles) para estudar a cinética de $\mathrm{P}$ em cabras em crescimento foi proposto por Vitti et al. (2000) e tem sido aprimorado (DIAS et al., 2006). Esses autores revisaram e estenderam o modelo de Vitti et al. (2000) para estudar os fluxos de cálcio em ovinos em crescimento recebendo diferentes fontes de cálcio na ração. Contudo, apesar de existir radioisótopos para estudar o cálcio no organismo $\left({ }^{45} \mathrm{Ca}\right)$, poucas são as informações sobre o uso desse mineral.

\section{FONTES DIETÉTICAS}

Como os minerais são definidos como um conjunto de elementos inorgânicos que constituem o corpo dos animais que não são sintetizados pelo organismo, eles necessitam ser obtidos por meio da dieta, devendo ser inseridos e contabilizados como nutrientes das rações. Dessa maneira, na formulação de dietas para ruminantes os minerais consistem em um importante nutriente e pode ser originado tanto de produtos inorgânicos como de ingredientes de origem vegetal.

Dentre as fontes orgânicas de cálcio, a polpa cítrica destaca-se por ser um subproduto da indústria de suco de laranja (o Brasil é o maior produtor mundial), o que garante a oferta desse ingrediente no mercado nacional. De acordo com o NRC (1985), o calcário calcítico, a farinha de conchas de ostras e o fosfato bicálcico são os principais suplementos de $\mathrm{Ca}$ utilizados na alimentação animal, sendo que as fontes inorgânicas proporcionam melhor aproveitamento de Ca pelos animais (VITTI et al., 2006).

O P pode ser ingerido na forma de ácido fítico, fosfolipídeos, ácidos nucleicos e outros compostos quando a alimentação fornecida for a base de vegetais. A concentração média de P nos grãos está entre 3,5 e 4,5 g/kg MS e nas forrageiras entre 2,5 e 3,0 g/kg MS, já nos suplementos vegetais proteicos encontram-se entre 5 e 12 g/kg MS (SUTTLE, 2010). No caso de ruminantes, $\mathrm{o} \mathrm{P}$ de origem vegetal possui grande disponibilidade devido à presença de fitases bacterianas no rúmen, entretanto não atende as exigências de $\mathrm{P}$ pelos animais.

Existem fontes de fósforo de origem animal como farinha de ossos, farinha de carne e farinha de peixe muito utilizadas no passado, mas atualmente é proibido o consumo por animais 
ruminantes devido à ocorrência da doença Encefalopatia Espongiforme Bovina (BSE, comumente conhecida como doença da vaca louca) na Europa.

Desse modo, no Brasil o fosfato bicálcico é a forma mais utilizada de suplementação de P. É uma fonte de excelente qualidade, porém de custo elevado, podendo representar de $75-85 \%$ do custo final da mistura. Com isso, criadores lançam mão do uso de fertilizantes fosfatados e os fosfatos de rocha in natura vendidos por preços mais acessíveis. No entanto, há uma contaminação desses fosfatos com diversos outros minerais (frequentemente o flúor) o que inviabiliza seu aproveitamento pelo animal. A produção de fosfato bicálcico utiliza o ácido fosfórico presente na rocha após um processo anterior de purificação, o que resulta em níveis aceitáveis de flúor (ANDRIGUETTO et al., 1990).

Trabalhos comparando fontes de P e de Ca ainda estão em desenvolvimento (DIAS et al., 2007; ROQUE et al., 2007; TEIXEIRA et al., 2011) para que, em um futuro breve, possamos ter mais opções de fornecimento desses minerais para os ruminantes.

É válido salientar que o $\mathrm{Ca}$ e $\mathrm{P}$ dietéticos estão associados no metabolismo sendo preconizado uma relação de $\cong 2: 1(\mathrm{Ca}: \mathrm{P})$, a depender da categoria e espécie, para a otimização da taxa de absorção. Assim, o desbalanço de um desses minerais interfere na homeostase de ambos.

\section{CÁLCIO}

O cálcio é o mineral mais abundante no corpo e $99 \%$ são encontrados no esqueleto. O esqueleto não só proporciona uma estrutura de suporte para os músculos bem como protege os órgãos e tecidos, incluindo a medula óssea, mas também é articulado para permitir o movimento, e é maleável para permitir o crescimento.

A pequena proporção (1\%) de cálcio do corpo que se situa fora do esqueleto é importante para a sobrevivência. Pode ser encontrada como o íon livre, ligada a proteínas séricas e complexado com ácidos orgânicos e inorgânicos. O cálcio ionizado (50-60\% do total de cálcio no plasma) é essencial para condução do sistema nervoso, contração muscular e a sinalização celular. Alterações nas concentrações de íons cálcio dentro e entre as células são modulados pela vitamina D3 e pelas proteínas de ligação ao cálcio (calmodulina e osteopontina). O cálcio ainda pode estabilizar ou ativar algumas enzimas e é necessário para a coagulação do sangue, o que facilita a conversão da protrombina em trombina, que reage com o fibrinogênio para formar o coágulo de sangue, a fibrina (Suttle, 2010).

\section{METABOLISMO DO CÁLCIO}

O cálcio é absorvido a partir da dieta de acordo com a necessidade por um processo 
regulado hormonalmente no intestino delgado (SCHNEIDER et al., 1985;. BRONNER, 1987) até aos limites estabelecidos pela dieta e pelo movimento líquido de cálcio para dentro ou para fora do esqueleto. Quanto ao metabolismo do cálcio, os estudos físico químicos comprovam que as trocas de cálcio entre os ossos e fluidos corporais ocorrem por dois processos: a) trocas iônicas, que correspondem ao processo rápido, na superfície óssea, quando o excesso de cálcio é incorporado à molécula de fosfato tricálcico; b) trocas lentas ou processos de recristalização, que correspondem à penetração de cálcio trocável no interior do osso (BRONNER, 1987).

\section{CONTROLE DA ABSORÇÃO DE CÁLCIO}

O cálcio é absorvido por um processo ativo no intestino delgado, sob o controle de dois hormônios: o hormônio da paratireóide, paratormônio (PTH) e a forma fisiologicamente ativa da vitamina D3, di-hidroxicolecalciferol $\left(1,25(\mathrm{OH})_{2} \mathrm{D}_{3}\right.$, também conhecido como o calcitriol) (SCHNEIDER et al., 1985; BRONNER, 1987). A glândula paratireóide responde a pequenas reduções na cálcio iônico no líquido extracelular através da secreção de PTH. Este estimula a dupla hidroxilação da vitamina D3, em primeiro lugar a 25-OHD3 no fígado e, em seguida, para $24,25(\mathrm{OH})_{2} \mathrm{D}_{3}$ ou $1,25(\mathrm{OH})_{2} \mathrm{D}_{3}$ principalmente nos rins, mas também na medula óssea, pele e na mucosa intestinal (NORMAN;HURWITZ, 1993). Ativado, $1,25(\mathrm{OH})_{2} \mathrm{D}_{3}$ abre os canais de cálcio na mucosa intestinal para facilitar a absorção de cálcio e é transferido com a ajuda de uma proteína ligada ao cálcio, calbindina. Dessa forma, ovinos tratados com $1,25(\mathrm{OH})_{2} \mathrm{D}_{3}$, aumentam a taxa de absorção e retenção de Ca (BRAITHWAITE, 1980).

A parcela de absorção de cálcio em ovinos mostram que a absorção de cálcio tem um limite de cerca de 0,68 para todos alimentos, incluindo forragens. No entanto, esta regra não se aplica quando ovelhas são alimentadas com dietas desequilibradas. Quando o fornecimento de cálcio é excessivo e as concentrações no intestino superior a $1 \mathrm{mmol} \mathrm{L}-1$, o cálcio é passivamente absorvido e mecanismos homeostáticos são invertidos pela secreção de calcitonina, que inibe a hidroxilação intestinal da vitamina D3 (BRAITHWAITE, 1980). Em tais circunstâncias, o cálcio pode ser absorvido a partir do rúmen (UPPAL et al., 2003).

Braithwaite; Riazuddin (1971) avaliaram efeito de idade e níveis de Ca dietético em carneiros sobre o metabolismo de cálcio e concluíram que a quantidade absorvida em animais jovens depende da ingestão mas que a porcentagem de Ca dietético absorvido é similar. Contudo, para animais mais velhos a quantidade de $\mathrm{Ca}$ absorvido não varia com a ingestão mas decresce com o avançar da idade. Além disso, esses autores observaram aumento da absorção de Ca em animais jovens em crescimento foi acompanhada por uma diminuição da velocidade de reabsorção óssea, mas a taxa de acreção óssea permaneceu inalterada. Alterações de níveis de Ca 
na dieta em animais mais velhos não teve qualquer efeito sobre qualquer um destes dois processos, contudo, ambas as taxas de acreção e reabsorção do osso diminuiu com a idade. Os resultados indicam que a reabsorção óssea é a principal via que rege a homeostase de $\mathrm{Ca}$ (BRAITHWAITE, 1974) e a taxa de absorção de Ca é uma reflexão do estado de metabolismo do Ca e não ao grau de disponibilidade do Ca no alimento. Em animais jovens em crescimento a eficiência de absorção diminuiu de cerca de 40\% a 2-3 meses para 36\% em 9 meses.

Existem evidências consideráveis de que a absorção de $\mathrm{Ca}$ em animais adultos pode, sob condições de depleção esquelético grave, ser retomada a uma taxa que se aproxima à observada na infância ao apresentar aumento de absorção e resultando em maior retenção. Também têm sido relatados em ovelhas no final da lactação, após um período de saldo negativo prolongado durante a gestação e lactação (BRAITHWAITE et al., 1970). Trabalhos sugerem que este aumento na quantidade de $\mathrm{Ca}$ absorvido por animais adultos pode ser um resultado do aumento transporte ativo de $\mathrm{Ca}$ em todo o intestino. Entretanto, embora a taxa de absorção a partir do intestino delgado aumentam de forma constante ao longo da gestação, a demanda extra de Ca durante este período são atendidas principalmente por reabsorção óssea (BRAITHWAITE et al., 1970).

É válido ressaltar que a demanda fetal de Ca é superior em ovelhas com dois fetos do que em ovelhas com gestação simples e geralmente é acompanhada pela diminuição das taxas de absorção intestinal e de reabsorção óssea. Para Braithwaite et al. (1970), o balanço de Ca materno permanece negativo até cerca de 40 d após o parto. Neste momento, a taxa de reabsorção do osso diminui rapidamente e as taxas de deposição óssea e de absorção de Ca a partir do intestino são respectivamente três e quatro vezes maior do que no momento da concepção. $\mathrm{O}$ balanço de $\mathrm{Ca}$ nas ovelhas torna-se, assim, positivo e continua a aumentar assim como perdas de Ca no leite diminui progressivamente.

\section{MOVIMENTOS DO CÁLCIO PARA O ESQUELETO}

O fluxo líquido de cálcio para dentro ou para fora do esqueleto desempenha um papel importante na regulação das concentrações circulantes de cálcio iônico e, assim, a absorção de cálcio. Filhotes de mamíferos nascem com ossos mal mineralizados enquanto não recebem cálcio suficiente para mineralizar plenamente todo o crescimento ósseo que o leite provém (AFRC, 1991). Após o desmame existe normalmente um aumento progressivo na mineralização óssea em cordeiros (FIELD et al., 1975), estimulado pelo aumento de exercício e de peso corporal.

Braithwaite e Riazuddin (1971) concluíram que para cada mg de Ca absorvido acima da média basal de $22 \mathrm{mg} / \mathrm{kg} /$ dia necessários para a manutenção, aproximadamente $0,93 \mathrm{mg}$ é retido pelo animal. Em contrapartida, cerca de um quinto de cálcio no esqueleto é mobilizado em ovinos 
(BRAITHWAITE, 1983c) devido ao parto e ao início da lactação. Uma redução durante o periparto na densidade óssea pode ser detectado tanto em ovelhas e cabras (LIESEGANG, 2008). O processo de reabsorção ocorre uma vez que não é diminuído através do fornecimento de cálcio dietético (AFRC, 1991) ou proteína (CHRISP et al., 1989; RAJARATNE et al., 1990) e não é necessariamente acompanhada por hipocalcemia (BRAITHWAITE, 1983a).

\section{CONTROLE HORMONAL DO CÁLCIO DO ESQUELETO}

Os hormônios que facilitam a absorção de cálcio também regulam os fluxos para o osso, mas os mecanismos são complexos. Os receptores nucleares para $1,25(\mathrm{OH})_{2} \mathrm{D}_{3}$ sobre os osteoblastos e condrócitos facilitam o acúmulo de cálcio. Os receptores para PTH são encontrados ligados a proteínas reguladoras (g) em órgãos como os rins e cérebro, bem como na glândula paratiróide. A acreção de cálcio e reabsorção são acoplados durante o crescimento (BRAITHWAITE; RIAZUDDIN, 1971), mas é desacoplada no final da gestação e início de lactação, em parte, através de reduções na atividade de osteocalcina - um hormônio que promove o crescimento ósseo. As concentrações séricas de osteocalcina diminuiem antes do parto e permanecem baixas durante pelo menos 14 dias, interrompendo o crescimento do osso para reduzir a necessidade por cálcio.

O tecido mamário pode regular a expressão e a liberação do hormônio PTH e a proteína relacionada com PTH (PTHrP). PTHrP em seguida, entra na circulação materna e imita PTH. Os osteoclastos respondem a $1,25(\mathrm{OH})_{2} \mathrm{D}_{3}$ via ocitocinas liberadas por osteoblastos (NORMAN; HURWITZ, 1993) e ao estradiol, e aumenta a sensibilidade para PTHrP. A calcitonina parece ter um papel importante em limitar a reabsorção óssea durante a lactação, mas isso não impede a regulação da absorção de cálcio (TUCEK et al., 2014).

\section{EXCREÇÃO DE CÁLCIO}

A excreção endógena fecal de cálcio $\left(\mathrm{F}_{\mathrm{eca}}\right)$ é geralmente afetada por mudanças na oferta dietética de cálcio, e a diferença entre ingestão e excreção fecal de cálcio (absorção aparente) em estudos de balanço pode ser ajustado para fornecer valores para a absorção verdadeira de cálcio em ruminantes (ARC, 1980). O aumento na ingestão de matéria seca estão associados com aumentos proporcionais em $\mathrm{F}_{\text {eca }}$ em ovinos recebendo dietas ricas em concentrado (AFRC, 1991) e uma relação semelhante aplica-se a dietas com volumoso (CHRISP et al., 1989). As perdas de 0,6-1,0 g kg-1 $\mathrm{F}_{\text {eca }}$ CMS têm sido relatados para os cordeiros recebendo volumoso e concentrado 
(ROQUE et al., 2007), mas prejuízos ainda maiores (até a 50 mg kg-1 de Ca peso vivo (PV)) têm sido relatados em cordeiros (CHRISP et al., 1989).

Braithwaite e Riazuddin (1971) mostraram que um aumento da ingestão dietética de Ca por animais jovens em crescimento resultou numa ligeira mas significante aumento na perda endógena fecal, enquanto que aumentos no consumo de animais mais velhos não teve nenhum efeito apreciável. Isto sugere que a perda fecal endógena pode estar relacionado com a absorção, uma vez que a quantidade de Ca absorvido também aumentou nos animais jovens, mas não nos mais velhos. Além disso, embora os valores médios ingestão dietética de Ca animais dois e 70 meses de idade foram quase idênticas, os valores médios de Ca fecal endógeno foram bastante diferentes $(24,8$ e 14,1 mg/d por $\mathrm{kg}$, respectivamente) como também eram as taxas de absorção $(43,2$ e $17,6 \mathrm{mg} / \mathrm{kg}$ por $\mathrm{d})$.

Braithwaite (1974) relata que quando fornecemos uma dieta pobre em Ca impossibilitando assim o animal de atisfazer suas necessidades de manutenção, os carneiros reduzem lentamente a excreção endógena fecal de $\mathrm{Ca}$, como retrato do aumento no aproveitamento de $\mathrm{Ca}$ pelo organismo devido à privação. Por outro lado, a excreção endógena fecal é consideravelmente mais elevada em ovelhas em lactação do que em animais gestantes (BRAITHWAITE et al., 1970).

Excreção urinária de cálcio tende a permanecer baixa e constante, independentemente do status de cálcio, com média de $5 \mathrm{mg} / \mathrm{d}$ por $\mathrm{kg}$ (BRAITHWAITE; RIAZUDDIN, 1971). A retenção de cálcio é, portanto, mais ou menos equivalente a absorção aparente, e um consumo de cálcio marginal reflete o valor de cálcio fornecido.

\section{EXIGÊNCIA DE CÁLCIO}

A exigência de cálcio líquido para o crescimento é quase inteiramente para o crescimento ósseo, mas é particularmente difícil de definir. Não houve tentativas com sucesso para definir as necessidades de cálcio de ovelhas por meio de ensaios de alimentação e assim é necessário recorrer às estimativas fatoriais de exigência. Infelizmente, estes têm variado consideravelmente entre os comitês de predição de exigência, em grande parte devido a discordâncias sobre um coeficiente de absorção real de cálcio. O AFRC (1991) descobriram mais evidências para apoiar o uso de uma absorção de cálcio máxima de 0,68.

As características importantes de tais exigências estimadas são as seguintes:

- Requisitos para cordeiros diminuem com a idade, mas aumentam com a taxa de crescimento;

- Requisitos para as ovelhas sobem rapidamente no final da gestação a um nível igual ao de lactação. 
A quantidade média de Ca que tem de ser absorvido para a manutenção é de $22 \mathrm{mg} / \mathrm{kg} / \mathrm{dia}$ e o máximo eficiência de absorção de Ca para ovelhas adultas alimentadas 50\% feno e 50\% ração concentrada é de aproximadamente 33\%. Portanto, ovelhas de $50 \mathrm{~kg}$ de PV requer uma ingestão dietética média de Ca 33 g/d para a manutenção (BRAITHWAITE; RIAZUDDIN, 1971).

\section{HIPOCALCEMIA}

O termo hipocalcemia bioquímica é utilizado para descrever uma condição clínica que se desenvolve no momento do parto. É caracterizada por inquietação, cegueira aparente, paralisia ruminal e, no pior dos casos, decúbito, tetania e morte. Sintomaticamente e até certo ponto etiologicamente, hipocalcemia se assemelha a toxemia da prenhez (uma consequência da deficiência de energia), sendo mais provável de ocorrer em ovelhas de parto duplo expostas a uma alteração ou escassez de alimentos e/ou estressados por transportes ou condições climáticas adversas.

A hipocalcemia e toxemia da gestação podem ser distinguidas bioquimicamente pela presença de níveis baixos de cálcio no plasma (a primeira) ou elevadas concentrações de betahidroxibutirato (a última), mas cada uma é susceptível de se desenvolver como consequência do outro, pois a perda de apetite é um sintoma de ambas condições e os níveis de cálcio e energia são simultaneamente diminuídos. Além disso, a hipocalcemia é muitas vezes acompanhada de hipomagnesemia e pode explicar a vasta gama de sinais clínicos associados à hipocalcemia, que incluem convulsões.

A hipocalcemia raramente afeta ovelhas em sua primeira gestação e é fisiologicamente semelhante a febre do leite em vaca em que é causada por falha no fornecimento para atender à crescente demanda por cálcio. No entanto, o início é antes do parto. Não há clara associação com baixo cálcio na dieta, indicando a importância da mobilização de cálcio do esqueleto. As sugestões de que o excesso de fósforo alimentar predispõe a hipocalcemia pode ser explicado por uma reabsorção óssea retardada. Há um desacordo sobre o papel do excesso de magnésio, mas o excesso de potássio pode predispor à doença. A hipocalcemia pode também ocorrer no final de uma seca, quando uma alimentação rica em nutrientes fique disponível depois de um período de alimentação de grãos de baixo teor de cálcio (SUTTLE, 2010).

\section{FÓSFORO}

O fósforo é o segundo mineral mais abundante no corpo do animal e cerca de $80 \%$ são encontrados nos ossos e dentes. A formação e manutenção de osso são quantitativamente as 
funções mais importantes de fósforo, e as alterações na estrutura do osso e a composição que resultam de privação de fósforo são, em muitos aspectos o mesmo que os descritos para a privação de cálcio. O fósforo é, no entanto, necessário para a formação da matriz óssea orgânica, bem como a mineralização dessa matriz. Os restantes $20 \%$ do fósforo do corpo é amplamente distribuída nos fluidos e tecidos do corpo, onde serve uma variedade de funções essenciais. O fósforo é um componente de ácidos desoxi e ribonucleico, que são essenciais para o crescimento e diferenciação celular. Como fosfolipídeos, contribui para a fluidez da membrana celular e integridade e à mielinização dos neurônios; e como o fosfato $\left(\mathrm{PO}_{4}\right)$ ajuda a manter osmolaridade e o equilíbrio ácido-base. O fósforo também desempenha um papel vital em uma série de funções metabólicas, incluindo a utilização de energia e transferência via AMP, ADP e ATP, com implicações na gliconeogênese, o transporte de ácidos graxos, aminoácidos e síntese de proteínas e atividade da bomba de íons sódio/potássio (SUTTLE, 2010).

Em ruminantes, os requisitos do rúmen e da microflora ruminal também são importantes, e a síntese de proteína microbiana pode ser prejudicada em dietas de baixo fósforo (MORRIS ; RAY, 1939). O fósforo está ainda envolvido no controlo do apetite (ainda não é totalmente compreendido) e na eficiência de utilização da ração. Síntese de P pode ter ocorrer nos tecidos, onde a sua forte afinidade para íons férricos fornece capacidade antioxidante e afinidade com íons de cálcio permite a participação na regulação dos genes, exportação RNA, DNA e reparação de sinalização celular (Suttle, 2010)

\section{ABSORÇÃO DE FÓSFORO}

A absorção de fósforo ocorre principalmente no intestino delgado proximal e é em grande parte não regulada em todas as espécies. Em ovinos desmamados (BRAITHWAITE, 1986), a absorção de fósforo é linearmente relacionada à ingestão de $\mathrm{P}$, com elevados coeficientes de absorção $(0,68-0,80)$. A desfosforilação e hidrólise de $\mathrm{P}$ a partir da ingestão de grãos e sementes liberam $\mathrm{PO}_{4}$ no rúmen e isto é, em grande parte, incorporada na proteína microbiana mas a degradação de $\mathrm{P}$ pode estar longe de ser completa. Fósforo microbiano é marginalmente menos bem absorvido do que $\mathrm{PO}_{4}$, que é, como outros ânions, prontamente absorvidos (BRAVO, 2003a).

Braithwaite (1980) ao avaliar o efeito da dosagem de I- $\alpha$-Hidroxicolecalciferol (análogo sintético do $\left(1,25(\mathrm{OH})_{2} \mathrm{D}_{3}\right)$ sobre o metabolismo de cálcio e fósforo em ovinos castrados, encontrou num aumento significativo na absorção do cálcio e na absorção aparente de fósforo e, como consequência, a retenção mineral negativa normalmente associado com o pico da lactação foi inibida. 


\section{METABOLISMO DE FÓSFORO}

Segundo Bravo et al. (2003a), o P da dieta está disponível para absorção quando alcança os locais de absorção na forma de $\mathrm{Pi}$, portanto, a solubilização do mineral antes da absorção determinará a quantidade absorvida. Dependendo da forma química do $\mathrm{P}$ da dieta, a solubilização digestiva do $\mathrm{P}$ acontecerá pela solubilização química (fosfato inorgânico), pela liberação do $\mathrm{P}$ resultante do processo de digestão da matéria orgânica (P nos nucleotídeos, nos lipídeos, etc) ou de reações de hidrólise específicas (P fítico). A porção de $\mathrm{P}$ orgânico dos alimentos inclui o $\mathrm{P}$ fítico e o P contido nas moléculas de fosfolipídeos e/ou ácidos nucleicos. A forma em que se encontra o P nos alimentos varia muito entre eles.

Segundo Morris e Ray (1939), o teor de P na dieta altera a ingestão de alimentos por ovelhas e, consequentemente, o desempenho animal. Dietas com baixo P diminui a ingestão de alimentos e, possivelmente, pode ser o resultado de uma diminuição da secreção de sucos digestivos com uma diminuição da ingestão de P. Além disso, a digestibilidade da proteína diminuiu e é provavelmente o resultado de uma diminuição da secreção de sucos e enzimas digestivas, que parecem usar $\mathrm{P}$ em suas reações metabólicas.

É válido ressaltar que uma dieta com baixos teores de $\mathrm{P}$ afetam não somente o metabolismo de proteína mas também o metabolismo de cálcio. Young et al. (1966) ao trabalharem com ovelhas recebendo diferentes níveis de $\mathrm{P}$ na dieta, relataram que a taxa de deposição de cálcio nos ossos bem como a reabsorção óssea foi afetada negativamente como consequência de baixa disponibilidade de $\mathrm{P}$ na dieta.

Os resultados de Dias et al. (2009) indicam que ambas as disposições dietéticos e endógenos de $\mathrm{P}$ ao rúmen são aumentadas com doses superiores de $\mathrm{P}$ na dieta. No entanto, a contribuição relativa da secreção de $\mathrm{P}$ endógeno no fluxo total de entrada de $\mathrm{P}$ no rúmen diminui gradualmente à medida que a ingestão de $\mathrm{P}$ torna-se maior, indicando que esta secreção endógena é relativamente mais importante na ingestão menor de $\mathrm{P}$, como um meio de garantir uma quantidade mínima deste mineral para o rúmen.

\section{RECICLAGEM DE FÓSFORO}

A mensuração de absorção de $\mathrm{P}$ em ruminantes é complexa devido à secreção de fósforo na saliva, o que aumenta grandemente o fluxo de P para o rúmen (TOMAS, 1973). O fósforo salivar é absorvido de forma tão eficiente como Pi (AFRC, 1991), permitindo uma reciclagem considerável, mas as fezes fornece a principal via para excretar excesso de fósforo absorvido em dietas à base de forragem. As fezes contém fósforo bem como da dieta e de microrganismos do 
rúmen, e a absorção aparente amplamente medida subestima o valor de fósforo. A secreção salivar de fósforo é em grande parte determinada pela concentração de fósforo na saliva, o que é altamente correlacionada com níveis plasmáticos de fósforo (BRAVO et al., 2003b). Esses autores encontraram uma relação de P salivar:plasmático na ordem de 6,2:1 a 10,5:1 a depender da quantidade de $\mathrm{P}$ na dieta. A baixa ingestão de fósforo causa a queda no $\mathrm{P}$ salivar e plasmático, mas as perdas endógenas fecais continuam a ser a principal fonte de fósforo nas fezes (70-90\%) (DIAS et al., 2009).

Os ruminantes reciclam mais $\mathrm{P}$ mediante a saliva do que os animais não ruminantes. Esse fato pode ocorrer por dois motivos. Primeiro, a secreção de saliva é um aporte para os microrganismos do rúmen sendo uma fonte adicional de $\mathrm{P}$ e, em segundo, a secreção de saliva pode contribuir para a homeostase total do P. A saliva de bovinos contém aproximadamente 100 $\mathrm{mg}$ de P/dl, sendo 15 vezes maior que os níveis plasmáticos. Enquanto, que a saliva de ovelhas contém em média três vezes o nível de P da saliva de vacas (CHURCH, 1993).

A relação entre a ingestão de $\mathrm{P}$ e concentração salivar de $\mathrm{P}$ permanece incerto, embora tenha sido sugerido que a ingestão elevada de $\mathrm{P}$ diminui o fluxo de $\mathrm{P}$ salivar, enquanto que a menor ingestão de P reflete em um fluxo de P salivar constante (BRAVO et al., 2003b).

\section{EXCREÇÃO DE FÓSFORO}

Embora o fósforo fecal reflete a perda endógena, bem como o consumo de fósforo, as concentrações têm sido utilizadas para monitorar a resposta do animal em pastejo para suplementação de fósforo em pastagens deficientes tanto em nitrogênio como em fósforo. Um valor limiar crítico de $<2$ g P kg-1 fecal MS tem sido defendida e foi um valor significativo, sendo que Morris e Ray (1939) reportaram que a quantidade de P excretada na urina é apenas $1 \%$ do P total excretado. Um balanço negativo para ruminantes em pastejo levantaria a possibilidade de privação de fósforo sendo pouco ou nenhum fósforo excretado na urina devido a um consumo marginal de fósforo. Além disso, dietas deficientes em $\mathrm{P}$ faz com que a excreção de Ca na urina aumente na ordem de até $5 \%$ do total excretado comparado a uma dieta equilibrada com esses minerais (MORRIS; RAY, 1939). Dessa forma, uma deficiência de P conduz a uma deficiência também de Ca o que reforça o a estreita relação no metabolismo desses minerais.

Em dietas peletizadas, dietas altamente energéticas que estimulam pouca secreção salivar, a excreção significativa de fósforo urinária pode ocorrer e a ingestão de fósforo relativamente mais baixa, não permite a mineralização completa dos ossos, apesar do Pi plasmático permanecer normal (Braithwaite, 1984). No entanto, a maioria dos ovinos alimentados com dietas ricas em 
volumoso excretam pouco fósforo em sua urina, mesmo em níveis plasmáticos Pi tão altas quanto 2 mmol L-1 (AFRC, 1991).

\section{CONSIDERAÇÕES FINAIS}

A utilização de radioisótopos no estudo de minerais pode se tornar uma prática definitiva, até o surgimento de uma nova técnica, devido a sua precisão e por evitar o sacrifício dos animais experimentais.

A taxa de absorção de Ca a partir do intestino aumenta de forma constante durante toda a gestação, entretanto é insuficiente para atender aos requisitos do final da gestação e início de lactação. Durante este período, o Ca extra é fornecido por aumento da reabsorção óssea. O equilíbrio de $\mathrm{Ca}$ materno torna-se negativa durante a gestação, mas no final da lactação o equilíbrio Ca materno torna-se positivo permitindo que os animais reabasteçam suas reservas esqueléticas.

Pesquisas relacionadas ao aproveitamento de $\mathrm{P}$ por ruminantes bem como as fontes dietéticas desse elemento ainda devem ser elaboradas devido ao elevado custo desse mineral na mistura mineral. Contudo, é necessário cautela uma vez que o fornecimento inadequado de P para os animais não só prejudica o metabolismo desse mineral mas também acarreta distúrbios no metabolismo proteico e de outros minerais.

\section{REFERÊNCIAS}

AGRICULTURAL AND FOOD RESEARCH COUNCIL - AFRC. Technical committee on responses to nutrients, Report 6 . A reappraisal of the calcium and phosphorous requirements of sheep and cattle. Nutrition Abstracts and Reviews (Series B), v.61, n.9, p.576-607, 1991.

AGRICULTURAL RESEARCH COUNCIL - ARC. The Nutrient Requirements of Ruminant Livestock. Slough: Commonwealth Agricultural Bureaux, 1980. cap. 1, p. 1-24; cap. 5, 183-200.

ANDRIGUETTO et al. Nutrição Animal. 4 ed. São Paulo: Nobel, 1990. 396 p.

BRAITHWAITE, G.D. Some observations in phosphorus homeostasis and requirements. Journal of Agricultural Science, Cambridge v.102, p.295-306, 1984.

BRAITHWAITE, G. D. The effect of changes of dietary calcium concentration on calcium metabolism in sheep. British Journal Nutrition, v.31, p.319-331, 1974.

BRAITHWAITE, G. D. The effect of dose rate of 1-a-hydroxycholecalciferol on calcium and phosphorus metabolism in sheep. British Journal Nutrition, v.44, p.183-191, 1980. 
BRAITHWAITE, G. D. The effect of 1-a-hydroxycholecalciferol on calcium and phosphorus metabolism in the lactating ewe. British Journal Nutrition, v.40, p.387-392, 1978.

BRAITHWAITE, G. D.; GLASCOCK, R. F.; RIAZUDDIN, SH. Calcium metabolism in pregnant ewes. British Journal Nutrition, v.24, p.661-670, 1970.

BRAITHWAITE, G. D.; RIAZUDDIN, SH. The effect of age and level of dietary calcium intake on calcium metabolism in sheep. British Journal Nutrition, v.26, p.215-225, 1971.

BRAITHWAITE, G.D. Calcium and phosphorus requirements of the ewe during pregnancy and lactation. 1. Calcium. Journal of Agricultural Science, Cambridge v.50, p. 711-722, 1983a.

BRAITHWAITE, G.D. Calcium and phosphorus requirements of the ewe during pregnancy and lactation. 2. Phosphorus. Journal of Agricultural Science, Cambridge v.50, p.723-730, 1983b.

BRAITHWAITE, G.D. Effect of $1 \alpha$-hydroxy cholecalciferol on calcium and phosphorus metabolism in sheep given high or low calcium diets. Journal of Agricultural Science, Cambridge v.96, p.291-299, 1983c.

BRAVO, D.et al. Quantitative aspects os phosphorus absorption in ruminants, part II.

Reproduction Nutrition Development, v.43, n.3, p.271-284, 2003 a.

BRAVO, D.et al. Quantitative aspects of phosphorus excretion in ruminants. Reproduction Nutrition Development, v.43, p.285-300, 2003 b.

BRONNER, F. Intestinal calcium absorption: mechanisms and applications. Journal of Nutrition, v.117, p.1347-1352,1987.

CHRISP, J. S.; SYKES, A. R.; GRACE, N. D. Kinetic aspects of calcium metabolism in lactating sheep offered herbages with different $\mathrm{Ca}$ concentrations and the effect of protein supplementation, British Journal of Nutrition, v.61, p.45-58, 1989.

CHURCH, D.C. The ruminant animal digestive physiology and nutrition. Englewood Cliffs: Waveland, 1993. 373-384p.

DIAS, R. S. et al. A revised model for studying phosphorus and calcium kinetics in growing sheep. Journal of Animal Science, v.84, p.2787-2794, 2006.

DIAS, R. S. et al. Rumen phosphorus metabolism in sheep. Journal of Agricultural Science, v.147, p.391-398, 2009.

DIAS, R. S. et al. Cinética do fósforo em tecidos de ovinos em crescimento alimentados com diferentes fontes de cálcio. Arquivo Brasileiro de Medicina Veterinária e Zootecnia, v.59, n.1, p. 203-209, 2007.

FIELD, A.C.; SUTTLE, N.F.; NISBET, D.I. Effects of diets low in calcium and phosphorus on the development of growing lambs. Journal of Agricultural Science, Cambridge v.85, p.435$442,1975$.

GRACE, N. D. Amounts and distribuition of mineral elements associated with fleece-free empty body weight gains in the grazing sheep. New Zealand Journal of Agricultural Research, v.26, p. 59-70, 1983. 
GRACE N. D.; WATLINSON, J. H.; MARTINSON, P. L. Accumulation of minerals by the foetus(es) and conceptus of single- and twin-bearing ewes. New Zealand Journal of Agricultural Research, v.29, p. 207-222, 1986.

MORRIS, S.; RAY, S.C. The effect of a phosphorus deficiency on the protein and mineral metabolism of sheep, Biochemical Journal, Aug v.33, n.8, p. 1209-1216, 1939.

NATIONAL RESEARCH COUNCIL - NRC. Nutrient requirements of sheep. 6.ed. Washington, D.C.: National Academy Press, 1985. 99p.

NORMAN, A.W.; HORWITZ, S. The role of vitamin D endocrine system in avian bone biology. Journal of Nutrition, v.123, p.310-316, 1993.

RAJARATNE, A. A. J.et al. The effect of variation in dietary protein or mineral supply on calcium and phosphorus metabolism in lactating ewes. British Journal of Nutrition, v.64, p.147-160, 1990.

ROQUE, A.P. et al. True digestibility of calcium from sources used in lamb finishing diets. Small Ruminant Research, v.71, p.243-249, 2007.

SCHNEIDER, K.M.et al. A short-term study of calcium and phosphorus absorption in sheep fed on diets high and low in calcium and phosphorus. Australian Journal of Agricultural

Research, v.36, p.91-105, 1985.

SUTTLE, N.F. The mineral nutrition of livestock. 4.ed. Wallingford, UK: CABI International, 2010. 579p.

TEIXEIRA, S. et al. Fontes de fósforo em suplementos minerais para bovinos de corte em pastagem de Cynodon nlemfuensis Vanderyst. Revista Brasileira de Zootecnia, v.40, n.1, p.190199, 2011.

TOMAS, F. M. Parotid salivary secretion in sheep: its measurement and influence on phosphorus in rumen fluid. Quarterly Journal of Experimental Physiology, v.58, p.131-138, 1973.

TUCEK, Z. et al. IGF-I in grazing dairy ewes during late pregnancy and lactation and its correlation to biochemical markers of bone metabolism. Veterinarski Arhiv, v.84, p.331-345, 2014.

UPPAL, S. K.; WOLF, K.; MARTENS, H. The effect of short chain fatty acids on calcium flux rates across isolated rumen epithelium of hay-fed and concentrate-fed sheep. Journal Animal Physiology and Animal Nutrition, v.87, p.12-20, 2003.

VITTI, D.M.S.S. et al. A kinetic model of phosphorus metabolism in growing goats. Journal of Animal Science, v.78, p.2706-2712, 2000.

VITTI, D.M.S.S. et al. Effects of dietary supplementation on phosphorus metabolism in sheep. Journal of Animal and Veterinary Advances, v.4, p.356-359, 2005.

VITTI, D.M.S.S. et al. Metabolismo de cálcio em ovinos em crescimento sob suplementação com diferentes fontes de cálcio: aplicação e comparação de dois modelos matemáticos. Revista Brasileira de Zootecnia, v.35, n.6, p.2487-2495, 2006. 
YOUNG, V. R.; LUICK, J. R.; LOFGREEN, G. P. The influence of dietary phosphorus intake on the rate of bone metabolism in sheep. British Journal of Nutrition, v.20, p.727-732, 1966. 